The issue may well turn on the question of numbers, and here again it should be noted that those who urge that the question of the number of university students in general requires reconsideration at the present time are prepared to restrict numbers so as to give the universities an opportunity of putting an end to the overerowding which militates against high standards. They lay the emphasis first on establishing conditions for creative work-for staff as well as for students. Apart from such wider questions as the appropriate balance between the arts and the science side, and the position of technological studies, having fuller regard to the fact that the university is not the only form of advanced education, investment in adequate library provision, travel grants and research scholarships and those amenities which facilitate contacts between students may be a wise step at the present time, even if such expenditure involves fewer university awards by local authorities, for example.

This aspect of the work of the British Council requires consideration in relation to that of the universities and particularly in regard to the extent to which adequate provision is made for the extension of libraries, halls of residence and the like, which were strongly urged by the University Grants Committee in its last report. The overseas student in this respect does not differ from other students : he will gain most from a university according to the extent to which he participates in the general undergraduate life. In bis recent life of Lord Keynes, R. F. Harrod observes, in respect of education at Oxford and Cambridge, that discussion with other undergraduates has, by general consent, played a large part in stimulating the creative and logical powers and in assisting the transition from the commonplace to the mature mind.

It is encouraging to find this point so well stressed in the pamphlet "Introduction to a University" which has recently been published by the University of Birmingham. The pamphlet is, indeed, intended to give guidance on university education, and the careers open to students, to the sixth forms of schools. It does this in a way which should both help those who ultimately enter the university to profit most fully from what the university has to offer and, no less important, assist others who are in outlook, temperament or in other ways unsuitable for a university course to decide against seeking to enter a university.

Reduction of university expenditure may well be a false economy for the nation, even when defence requirements are more stringent; but that is not to say there are no opportunities for eliminating unessentials at present. It does mean, however, that the universities should be clear as to priorities and as to the ways in which standards can best be maintained. Above all, it supplies a further compelling reason for placing the responsibility for the general oversight and distribution of Exchequer grants to universities and to higher technological institu. tions fairly and squarely on the shoulders of one body.

\section{BEHAVIOUR OF COLLOIDAL ROCKET PROPELLANTS}

Internal Ballistics of Solid-Fuel Rockets

Military Rockets using Dry-processed Double-Base Propellant as Fuel. By R. N. Wimpress. Pp. xii 214. (London: McGraw-Hill Publishing Co., Ltd., 1950.) 38s. $6 d$.

THIS book is limited to work carried out at the California Institute of 'Technology, and is mainly on one colloidal propellant, J.P.N. Nevertheless, it gives a fair summary of most of the work on colloidal rocket propellants carried out in Allied countries, and to some extent in Germany too, up to 1945. In other laboratories other propellants gave rise to the same problems, which were tackled in much the same way. For example, British workers were using interrupted burning techniques to study erosive burning in 1941, the phenomenon having been noted after unpredicted interruptions some years earlier.

The book starts with a description of the thermodynamic properties of propellant gases and methods of calculating them, followed by a description of the dependence of burning-rate on physical factors such as pressure and gas flow. Next follows the simple theory of an ideal rocket with adiabatic flow through the nozzle. Modifications are then introduced to take into account the pressure gradient along the combustion chamber, frictional and turbulent losses in the gas, and the effect of gas flow on the burningrate. In order to obtain simple analytical solutions some approximations are made, of which perhaps the most important is the assumption that the rate of burning of the propellant is everywhere equal to its average rate, so that the cross-sectional area of the propellant remains uniform along its length. Since the same approximations are made in analysing experimentel firings, however, the theory must give good predictions of the behaviour of rockets the proportions of which do not differ too widely from those used in the experimental firings.

A number of minor factors affecting performance, such as heat loss to the metal wall and deformation of the propellant under stress, are treated as perturbations of the given solutions. It is interesting to note that bursting of rounds that have been heated. before firing is mainly due, not to collapse of the softened propellant under longitudinal stress, but to small deformations within the elastic range, which block the conduit sufficiently to raise the pressure at the closed end of the chamber above its bursting point.

The mathematics is very simple and set out in great detail. All the results deduced are copiously illustrated by graphs, of which there are more than eighty. Sufficient numerical information is given for the design of rocket motors using J.P.N. propellant for almost any required performance, but only a little information is given for a few other propellants. The description of experimental apparatus is confined to ten pages, of which five are devoted to the Bourdon pressure gauge as modified for optical recording. One form of apparatus for interrupting burning, perhaps the most important tool in the hands of workers in this field, is also described.

While primarily a handbook for the specialist, this book may be read with interest by anyone concerned with military weapons. The production is excellent.
H. H. M. PIKE 